\title{
LOUÇA CHINESA E POESIA BRASILEIRA: CORA CORALINA EM CAMPO EXPANDIDO
}

\section{CHINESE CROCKERY AND BRAZILIAN POETRY: CORA CORALINA IN EXPANDED FIELD}

\author{
Rita Lenira de Freitas Bittencourt ${ }^{1}$
}

A heterotopia tem o poder de justapor

em um só lugar real vários espaços.

Michel Foucault. Ditos e Escritos.

\begin{abstract}
Resumo: Este artigo se ocupa de alguns poemas e um texto em prosa de Cora Coralina. São trabalhos onde se cruzam tempos e espaços, se recuperam sensações e dados da memória individual e coletiva e nos quais, simultaneamente, o caseiro e o interiorano se aproximam do distante e do estrangeiro. A partir da noção de campo expandido, desenvolvida pela teórica americana Rosalind Krauss, no artigo "Sculpture in Expanded Field", de 1979, que explora certa condição do poético e traz alguns elementos esculturais que podem auxiliar a definir estratégias teóricas de abordagem ao literário, entendemos a cena contemporânea na aproximação analítica e crítica a objetos, textos e imagens em movimento para fora das especificidades. Lugar da poesia e da prosa poética, a obra da poeta goiana circula sem constrangimentos ou amarras, anacrônica e deliberadamente transdisciplinar.
\end{abstract}

PALAVRAS CHAVE: poesia; história; literatura; campo expandido; Cora Coralina

Abstract: This article deals with some poems and prose texts of Cora Coralina. They are works where times and spaces intersect, sensations and data of individual and collective memory are recovered, and simultaneously, domestic and distant places are connected. From the notion of expanded field, developed by the American researcher Rosalind Krauss, in the 1979 article "Sculpture in Expanded Field", that addresses some conditions of poetical works and brings sculptural elements that can help define strategies of approach to literary, we understand the contemporary scene in the analytical and critical approximation to objects, texts and images, moving out of the theoretical specifics. Places of poetry and poetic prose, Coralina's poems expand without constraints in anachronistic and transdisciplinary way.

KEYWORDS: poetry; History; literature; expanded field; Cora Coralina.

\footnotetext{
${ }^{1}$ Doutora em Literatura pela Universidade Federal de Santa Catarina (2005).
} 
Os poemas de Ana Lins dos Guimarães Peixoto, de pseudônimo Cora Coralina (1889-1985) falam de sua cidade natal, Goiânia, capital do estado brasileiro de Goiás, em tempo presente e construída pelas marcas do seu passado colonial. Nesta direção, poderiam tratar de qualquer cidade brasileira tocada pela mão do conquistador, pelo trabalho dos negros, pelas ações de personagens típicos, como padres e soldados, formas e emblemas de um exterior já conhecido e satirizado, anos antes, por Gregório de Mattos, em relação a Bahia, ou por Tomás Antônio Gonzaga, em relação a Minas Gerais. Mas eles - os poemas e o texto aqui estudados - não são satíricos, ainda que movidos por um olhar desviante. Apoiados numa suposta "inocência" de enfoque infantil, recuperam, efetivamente, a contraparte das relações de poder: o cotidiano miúdo, o lado de dentro da casa - herdeira da "casa grande" senhorial - e o espaço doméstico que, por ser "de mulheres", manteve-se ao mesmo tempo participante e à margem dos grandes feitos, submetido a múltiplas formas de violência e apagamento. Em termos teóricos, são textos que produzem efeitos melhor captados por miradas dramatizadoras e por descontinuidades, nas formas do rizoma ou do mosaico e à meia voz, nas zonas de sombra.

Partindo dos poemas "Estória do Aparelho Azul-Pombinho" (de 156 versos, p. 63-67) e "O Prato Azul-Pombinho" ( de 242 versos, p.79-86), junto com a "Nota", em prosa, que os acompanha, subtitulada "De como acabou, em Goiás, o castigo dos cacos quebrados no pescoço" (de 21 parágrafos, p.87-90), tentarei uma breve operação de leitura/viagem/encontro ${ }^{2}$ na literatura e através dela, que vai operar um resgate alegórico de tempos e espaços culturais distintos e, simultaneamente, postos em contato. Além disso, por via marginal, acompanharei brevemente a mulher, o negro, o velho, a criança, o estrangeiro, procurando, nessas personagens e suas deliciosas e tristes "estórias", resgatar um pouco do que foi rasurado na memória literária e na memória histórica brasileiras, ambas entendidas no plural e em plano aberto.

Os dois poemas e a nota foram retirados de Poemas dos becos de Goiás e estórias mais, primeiro livro, publicado em 1965, quando Cora Coralina já tinha 75 anos. Utilizarei aqui a $17^{\mathrm{a}}$. Edição, de 1993 .Vale destacar que a poeta costumava afirmar nas entrevistas que

\footnotetext{
${ }^{2}$ Dedico este ensaio à Eleonora, colega que me apresentou Cora Coralina, e à Ana Luiza, professora, para quem, no século passado, eu escrevi outro trabalho, com os mesmos objetos retomados aqui. Por fim, à minha mãe, em memória.

${ }^{3}$ Uso a expressão "estórias" um tanto anacronisticamente, em menção explícita à autora Cora Coralina, que separa, em seus trabalhos, e, inclusive, no título da obra citada neste artigo, a História da estória.
} 
escrever versos e fazer doces eram a cara e a coroa de ações lúdicas e criadoras, desenvolvidas ao longo da vida. Por isso, em campo expandido, as palavras e a calda, os textos e os condimentos, compõem-se de uma única e mesma matéria, sobrepondo-se, na superfície da página ou na bandeja enfeitada com fitas, em uma única e sensível oferta aos sentidos. Ao amor de confeiteira junta-se uma sensibilidade às dores alheias que vai combinar em um mesmo prato, doçura, perfumes de essências e experiências agradáveis com sangue, castigos e desejos femininos de evasão.

\section{Poemas de cacos}

Estórias de estórias, os poemas "Estória do Aparelho Azul-Pombinho" e "O Prato Azul-Pombinho" são narrativos, "contados" pela personagem que "era Aninha”, que, por sua vez, ouvira contar de sua "bisavó - que Deus a tenha em bom lugar -"(v.1, primeiro poema) e “ - que Deus a tenha em glória -" (v.1, segundo poema). A temática é um preciosíssimo aparelho de jantar, de 92 peças, trazido da China a Goiás por ocasião da festa de casamento do sobrinho de um cônego endinheirado com uma das filhas da bisavó de Aninha.

O primeiro poema narra a vinda do aparelho de jantar, enfocando o passado como memória épica; o segundo, no futuro, descreve as sensações da menina Aninha diante do último prato, remanescente do tal aparelho que ela sequer conhecera, cujas ilustrações eram transformadas pela bisavó na lenda libertária da "princesinha Lui ", habilmente registrada à mão, em tom "azul-pombinho", como é descrita a pintura em azul e com motivos chineses que decoram a louça.

Uma rede "de correspondentes como era norma, naquele tempo"(v.18, 19) forma-se, especialmente e espacialmente, para a aquisição do aparelho: uma carta é entregue a alguém na Corte (Rio de Janeiro), daí passa para Lisboa, de Lisboa a Luanda, de Luanda a Macau, de Macau para os chineses, até que um artesão de Cantão, finalmente, "laborou o prodígio (no dizer de minha bisavó)" (v.35). Outra rede é construída no transporte:

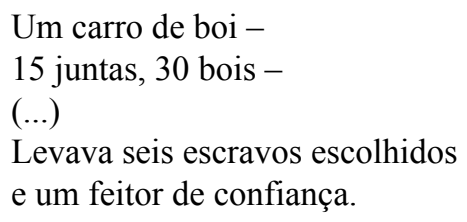

\footnotetext{
${ }^{4}$ A história de Lui, a princesinha chinesa, vai ser melhor desenvolvida no poema "O prato azul-pombinho": - "oh, encanto da minha meninice! -" (v.85, segundo poema). No entanto, é uma das linhas-mestras nos dois poemas, pois costura os planos, junta espaços e enreda imaginação e experiência. Por isso, talvez se possa afirmar que esta personagem é uma projeção das personagens de Aninha e sua bisavó e, de certo modo, vai figurar em contraponto à da menina Jesuína, da Nota.
} 


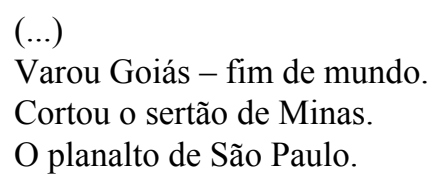

Foi receber o aparelho e mais sedas e xailes-da-índia

em Caçapava -

ponta dos trilhos da Dão Pedro Segundo -

ali por volta de 1860 e tantos.

Durou essa viagem, ir e voltar,

dezesseis meses e vinte e dois dias.

- As bodas em suspenso (CORALINA, 1993, v. 47,48; 53,54; 67-69; 70-76)

Enquanto, via correspondência, traçava-se a feitura e o itinerário do conjunto de louça, com "as bodas em suspenso", a jovem noiva, "sinhazinha de catorze anos"(v.77), "analfabeta", porque: "Diziam os antigos educadores:/ "- Mulher saber ler e escrever não é virtude."” (v. 88 - 90), tratava da confecção do seu "bragal", acompanhada pelas escravas "de dentro" que:

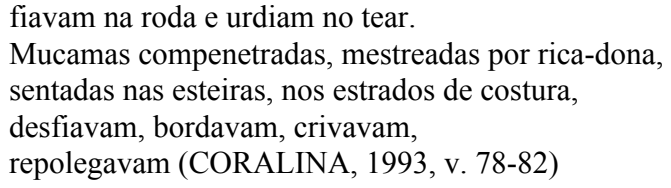

Nas malhas das múltiplas redes, trançando cada fio, os escravos participam dos eventos de modo muito efetivo, dando sustentação a eles e justificando "altruísticas" atitudes dos senhores: na festa de casamento, dois velhos são alforriados, e, mais tarde, é alforriado também, na pia batismal, um "crioulinho" que nasce no mesmo dia em que o primeiro filho do casal. No entanto, a lembrança da festa, um "mimo" de cartucho de papel verde recheado de "confeitos de ouro em filigrana", recebem apenas os "convidados graduados":

Governador da Província

Cônegos, Monsenhores, Padres-mestres

Capitão-mor.

Brigadeiros. Comendadores.

Juízes e Provedores. (CORALINA, 1993, v. 110-114)

Como as iniciais em maiúsculas tão bem expressam, trata-se dos poderosos em cujas mãos estão as decisões políticas, religiosas, jurídicas da região. Ou seja, constituem o lado "de fora" da casa, o plano exterior ao da narradora Aninha, e assim aparecem no poema: citados, enumerados, destacados pela pontuação. 
Só que essas estórias são o "presente e o futuro" de uma velha mulher, que, por sua vez, as transmite a uma menina ${ }^{5}$. É no ambiente doméstico que são memorizadas e se desenrolam, no plano da oralidade, transmitidas ao futuro, e é com o trabalho da gente "de dentro" que se formam, a partir dos minúsculos que se movimentam, o tempo todo, pelos textos.

No segundo poema, são "de dentro", também, as relações que se instauram pelo uso compartilhado do último prato do aparelho:

\author{
Às vezes ia de empréstimo \\ à casa da boa tia Nhorita. \\ (...) \\ No dia seguinte, voltava, \\ conduzido por um portador \\ que era sempre o Abdênago, preto de valor, \\ de alta e mútua confiança. (CORALINA, 1993, v.141-149)
}

E, com as relações de vizinhança e de troca, em torno do prato, aparecem os elementos da indústria caseira de doces, tão comuns nas zonas coloniais açucareiras, em listas de títulos que sugerem sabores, odores e palavras, em explosões sensoriais e afetivas:

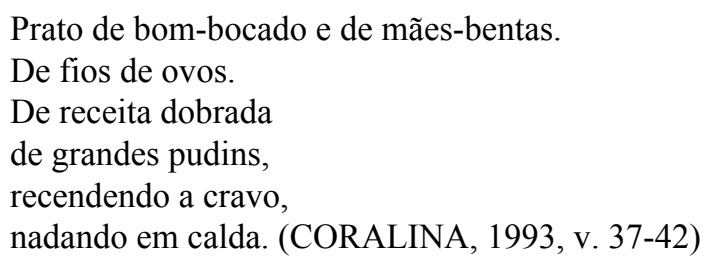

Quando o aparelho, que tinha muitas peças, reduz-se àquele prato, a menina ainda dá voz à bisavó, mas passa a ter uma participação ativa no poema, ao relatar suas sensações e ao ser responsabilizada e punida pela desastrosa quebra do objeto. Aparece, então, desdobrada, outra personagem feminina, uma princesa chinesa, o prato servindo de tela para sua história estrangeira - pela leitura das imagens, ela foge para o mar - o que cria uma tensão entre o cotidiano autoritário da casa de Goiás e a liberdade atemporal de um barco pintado, alimentando o imaginário da criança:

\footnotetext{
${ }^{5}$ Raul Antelo localiza, numa espécie de filologia às avessas do modernismo antropofágico, uma abertura sensorial à multiplicidade de registros. Comenta o teórico: "Mario de Andrade nos fornece, numa passagem da carta às Icamiabas, um poderoso estímulo para entender a história não mais como aquilo que se vê, mas sim como aquilo que se ouve." (ANTELO, 2016, p.13). Assim, é justamente na arte moderna, que foge aos constrangimentos de leituras espelhadas na natureza, que se podem combinar, por exemplo, as "Correspondências" de um Baudelaire e as indefinições em torno do espaço escultural em Krauss, Ou, até mesmo a labilidade do "entre-lugar", apontada por Silviano Santiago em relação à América Latina (1978).
} 
Eu era toda ouvidos.

Ouvia com os olhos, com o nariz, com a boca, com todos os sentidos, aquela história da Princesinha Lui, lá na China - muito longe de Goiás que tinha fugido do palácio, um dia, com um plebeu do seu agrado (CORALINA, 1993, v. 63-69)

Duas dimensões se instauram. De um lato, utilitário, o último prato, antes da quebra, enfeita as mesas nos aniversários, festas de cerimônia, cheio de doces e salgados, representante único de um fausto passado. De outro, "vazio" e em tempo de narração, no avesso da festa, guarda os segredos de uma estória passional e noturna que se monta em conexão de texto e imagens:

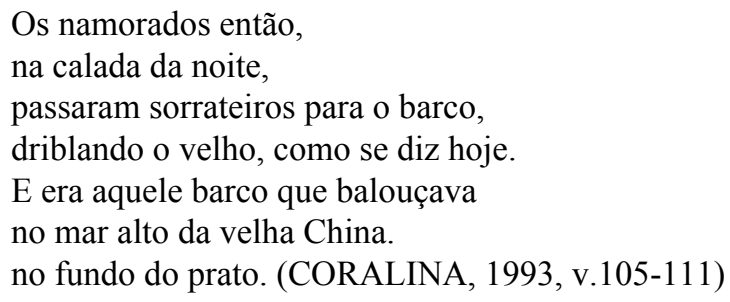

O "velho" era o mandarim, pai da princesa fugitiva, que tinha mandado atear fogo a um quiosque onde os amantes haviam se escondido. Lui, avisada a tempo por sua idosa ama, consegue escapar da morte. O papel da ama é decisivo e o poder é "driblado" pela solidariedade feminina. Todas essas figuras, em detalhes mínimos, estampam a superfície do prato e deleitam a menina que as lê/vê enquanto a bisavó se encarrega de montar o enredo.

Nota-se também a replicação da oralidade das narradoras, a primeira, a avó, e a que, no livro, assume esta função, e a segunda, Aninha, já adulta, ao utilizar as expressões "o velho" e "como se diz hoje" (v.108). Assim, a rede temporal se sustenta pela transmissão dos saberes entre as gerações, nos sentidos dados por Walter Benjamin em suas investigações sobre a tradição do narrador e no artigo traduzido como "Experiência e pobreza" (1994, p.114-119), por exemplo.

Quando o último prato é quebrado, a menina Aninha é apontada como culpada, sendo obrigada a usar, como punição, um dos cacos do prato pendurado no pescoço. E outra estória se mostra, a partir da "Nota", que prolonga os poemas, em mais um giro, que se dirige ao passado trágico da escravidão: trata de uma "cria", criança "nem escrava nem forra", que 
servia uma senhora "uma tal de D. Jesuína, dona de Teres-Haveres", segundo os dois parágrafos de apresentação. O objetivo da nota é explicar "De como acabou, em Goiás, o castigo dos cacos quebrados no pescoço". É que, tendo que usar um colar de cacos como castigo, a menina acaba morrendo, ferida por um deles enquanto dormia numa esteira, aos pés da cama da senhora:

A criança estava fria, endurecida e morta. A esteirinha encharcada. Durante a noite, no sono, uma aresta mais viva de um dos cacos serrilhados tinha cortado uma veiazinha do seu pescoço, e por ali tinha no correr da noite esvaído seu pouco sangue e ela estava enrodilhada, imobilizada para sempre. (CORALINA, 1993, p. 89)

É importante prestar atenção nessa menina morta, contraponto da Aninha tanto quanto a Princesinha Lui. Era neta de uma "escrava de dentro", de nome Prudência, que "Deu à sinhá vários crioulos de valor que mais enricaram a velha dona". Uma das filhas de Prudência, de nome Rola, torna-se "afilhada e alforriada na pia", tendo, por isso, por intercessão da madrinha, casado virgem e na igreja com um francês. No entanto, Rola morre em pouco tempo: "hética" (tuberculosa) e/ou "Diziam: gálico do marido" (sifilítica), deixando a filha ainda bebê, que foi batizada com o mesmo nome da madrinha - Jesuína.

Nesta "Nota", as escravas têm nome e, ironicamente, a vítima do castigo dos cacos tinha o da sua senhora, ou madrinha, já que não estava bem definida sua condição. É pelo sacrifício da menina Jesuína que à Aninha, tempos depois, é concedido usar apenas um dos cacos como castigo, fato que é antecipado no segundo poema:

\footnotetext{
Logo se torceu no fuso um cordão de novelão.

Encerado foi. Amarrou-se a ele um caco de bom jeito, em forma de meia-lua.

E a modo de colar, foi posto em seu lugar, isto é, no meu pescoço (CORALINA, 1993, v.221-226)
}

Contrariando o subtítulo da "Nota", este tipo de punição não acaba completamente: um "acidente" doméstico, ocorrido com uma insignificante "cria" da casa de uma das contemporâneas da avó de Aninha, apenas o suaviza. Envolvidas no mesmo sentido sacrificial estão, também, a escrava parideira que enche a casa de filhos, igualmente escravos, aumentando o patrimônio da dona; e também sua filha, que morre vomitando sangue e com sífilis, ainda que tivesse sido alforriada e gozasse do status de afilhada. 
A expressão "gálico", denominação da época para a sífilis, refere-se aos estrangeiros, franceses - da Gália - a quem, provavelmente, atribuía-se a introdução e propagação da doença em meio local. Ao aspecto positivo de um "outro" feminino, a estrangeira, corajosa e voluntariosa, que foge do autoritarismo paterno, contrapõe-se este, masculino e negativo, em que o desejo pelo que vem "de fora" torna-se concretamente nocivo.

Já a princesa oriental do fundo do prato continua no barco, flutuando eternamente com seu amado, sobre as ondas, numa história sem fim:

Eu era curiosa para saber o final da estória, Mas o resto, por muito que pedisse, não contava a minha bisavó.

Dali para a frente a estória era omissa.

Dizia ela - que o resto não estava no prato nem constava do relato.

Do resto, ela não sabia. (CORALINA, 1993, v.112-118)

O não encerramento dessa estória não impede que as outras, paralelas, tenham seus finais assinalados, propondo uma dramatização ficcional que se estende à história, contaminando-a formalmente e tornando-a, também, multifacetada.

\section{Vitral da história}

Vários espaços, várias metáforas, todas “caseiras”, mapeadas na superfície dos poemas e "Nota" de Cora Coralina, que partem do fragmento e nos quais se percebe, benjaminianamente, a ruína como alegoria e as possibilidades de "escovar a história a contrapelo" e "fazer saltar pelos ares o continuum da história"(Benjamin, 1994, p.222-232), sugerem imagens estriadas: colcha de retalhos, rede, rizoma, tela, renda, vitral.

Talvez, no contexto deste ensaio, o termo vitral seja, materialmente, mais adequado para abordar os movimentos de elaboração, transporte e destruição de um conjunto de louça, cujo fragmento é, inicialmente, um prato, que a seguir é reduzido a cacos. O caco seria uma unidade mínima de expressão máxima: faz reviver relações e estórias e também encerra a morte, em duplo sentido: testemunha a morte das relações pessoais e sociais e torna-se instrumento do sacrifício de uma criança.

O último prato, ele também uma sobra, instaura uma espécie de deslocamento do desejo, em perspectiva espaciotemporal, quando o imaginário se inclina para o "outro" - uma personagem-mulher-estrangeira que se rebela - e para onde convergem as atenções tanto de 
uma idosa quanto de uma menina. Uma, por apropriação, torna o objeto e a história que está nele algo muito seu, testemunha de sua própria existência; a outra, por curiosidade, ouve e assimila a história de sua bisavó e a que nele se registra.

Este prato com seus desenhos contribui, assim, para a construção de subjetividades, dando a ver a perspectiva da consciência de proximidades e distanciamentos e do equacionamento cultural delas. Desloca-se, assim, a posição dos sujeitos envolvidos: a bisavó, já velha, encontra ali algo que a liga ao passado e que a mantém viva, presente e ativa; a menina, vítima de uma educação repressora e autoritária, descobre seu ponto de fuga através das imagens, guiada pela voz da bisavó narradora de ficção. Assim, algo que supostamente pertenceria ao mundo exterior passa a ter um significado mais amplo, num espaço duplamente interior, tanto físico quanto psicológico, tornando-se formador.

O conjunto de louça se relaciona também ao deslocamento, pelas redes que forma: a de correspondentes, primeira, para sua encomenda e feitura, que atravessa oceanos e continentes; a de escravos, em seguida, para o transporte, que vai de Goiás a São Paulo, percorrendo a nação em formação; Estas duas redes, de certa forma, se ligam à terceira, das escravas comandadas pela noiva, que, enquanto espera, vai fazendo o enxoval. As duas primeiras se tecem mais no espaço e a segunda, no tempo. As duas primeiras são exteriores, ligadas mais ao "fora" da casa e a terceira é interior, muito "de dentro". Mas o que as põe em movimento é o casamento, um motivo que, na época, consegue envolver a todos:

O casamento era um dos fatos mais espaventosos em nossa vida patriarcal. Festa de durar seis, sete dias, simulando-se às vezes a captura da noiva pelo noivo, preparava-se com esmero a "cama dos noivos" - fronhas, colchas, lençóis, tudo bordado a capricho, em geral por mãos de freiras; e expostos no dia do casamento aos olhos dos convidados. Matavam-se bois, porcos, perus. Faziam-se bolos, doces e pudins de todas as qualidades. Os convivas eram de tal número que nos engenhos era preciso levantar barracões para acomodá-los. Danças europeias na casa-grande. Samba africano no terreiro. Negros alforriados em sinal de regozijo. Outros dados à noiva de presente ou de dote: "tantos pretos", "tantos moleques", "uma cabrinha"...(FREIRE, 1963, p. 391)

Ao que parece, a festa satisfaz tanto aos interesses casadoiros comumente atribuído às mulheres, quanto às necessidades econômicas da sociedade dirigida pelos homens e pela igreja. A casa, espaço doméstico, fora da legitimação oficial, por conta deste evento recebe uma atenção que a coloca momentaneamente no centro: a família como célula do social, o caco tomado pelo todo. O casamento, que serve de tema aos poemas, desencadeia relações 
intercambiantes e provoca transformações que deixam expostas, como num vitral, os pontos de tensão e diferenças nos interstícios de uma superfície fragmentada.

Um vitral é construído juntando-se pedaços de vidros de cores diferentes, para formar uma vidraça, que é a soma de todas as partes, mas que não se reduz a um todo orgânico, pois o mais interessante, talvez, sejam exatamente as marcas em destaque, aquelas onde os cacos se juntam. Por isso, a festividade das bodas é tão importante. Funciona como uma das linhas de força que costura os poemas e a "Nota".

Um vitral da história brasileira, literalmente, poderia constituir-se de vários "cacos textuais". Ao selecionar os dois poemas e a "Nota", cacos menores, restos, sobras saem das sombras e adquirem um protagonismo impensado, dando sustentação a um dos objetivos deste ensaio, que é o de empreender uma viagem por lugares de origem que também são de rasura. Uma visita à velha casa de Goiás, patriarcal e opressora, ao mundo narrado da menina-velha Aninha, num tempo passado-presente, faz mais que tensionar: acentua as ambiguidades. A casa é, de certa forma, uma prisão, mas que fornece, do seu interior, uma chave de libertação. As relações menores que se desenvolvem ali, naquele espaço fechado, justamente por serem menores, funcionam como uma carga de dinamite, implodindo-o silenciosamente.

\section{Campo expandido}

Ao tomar a produção da poeta goiana em campo comparatista, as reflexões em torno do escultural, elaboradas por Rosalind Krauss podem ser projetadas no campo das letras, ocupando, expansivamente, lugares teóricos amplos e transdisciplinares, cruzando a história com a ficção, misturando o próprio e o alheio e atravessando a memória individual e a coletiva. Segundo Kiffer e Garramuño, traduzindo e citando Krauss, em seu artigo já citado, expansão e indefinição se tornam sinônimos:

Lembremos a indefinição à que pretende dar nome o conceito: "Nos últimos dez anos coisas bem surpreendentes têm vindo a ser chamadas esculturas: estreitos corredores com monitores de televisão; grandes fotografias documentando o campo; espelhos colocados em ângulos estranhos em quartos comuns; linhas temporárias cortadas no piso do deserto. Nada, pareceria, poderia dar a essa heterogeneidade o direito de reclamar o que poderia ser significado pela categoria de escultura. Só se essa categoria foi tornada quase infinitamente maleável. (KIFFER, GARRAMUÑO, nota 2,2014, p.14) 
Assim, maleáveis, as personagens Aninha e sua bisavó, dos poemas e da "Nota" de Cora Coralina, participam do campo expandido da dicção de mulheres, que, por um lado, se identifica plenamente com o informe, com o não saber e com as artes do acaso:

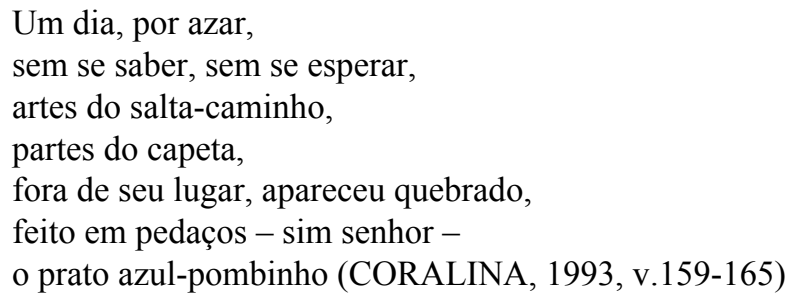

E, por outro lado, no encerramento da "Nota", partilha, sem grandes estranhamentos, as ambivalências do cuidado:

No meu sono de criança, tinha a sensação de uma sombra debruçada sobre mim. Era minha bisavó ajeitando o caco, tirando fora da coberta. / Não fosse acontecer com Aninha o que acontecera com a menina Jesuína, cria da D. Jesu. (CORALINA, 1993, par. 20-21)

Da escultura ao vitral, do íntimo ao êxtimo, em relação ao que Tamara Kamenszain denominou "vanguarda doméstica", não há, na escritura de mulheres, lados do avesso, temáticas desnecessárias ou a possibilidade do não dizer. Por isso é tão eloquente e potente sua definição da boca como o lugar da poesia:

A poesia não dá testemunho sobre isto ou aquilo: a poesia é a boca, é a única possibilidade de testemunhar. A poesia é a única que pode, depois que já sabemos que não se pode dizer nada, alcançar a verdade, inclusive como ausência de sentido. De modo que a poesia é uma boca que se abre ou que está sempre aberta, que não pode fechar, que quando fecha, vira estereótipo e quer "dizer algo". Mas quando está sempre aberta, entram nela todas as moscas. KAMENSZAIN, 2015, p.129)

Assim, no espaço-tempo presente, a leitura do passado, por ser de mulheres, adquire uma profusão de cores. Tem-se, nos movimentos apontados, uma visada literária na qual as geografias e culturas se estranham e se encontram - China, Macau - Brasil -, o que vai resultar num misto de desconexão e variedade de registros, por um lado; por outro, sendo o tema da

\footnotetext{
${ }^{6}$ No artigo, já bastante conhecido, "Bordado e costura do texto", diz Kamenzain, em relação ao tratamento da escrita pelas mulheres: "Costurar, bordar, cozinhar, limpar, quantas maneiras metafóricas de dizer escrever. (...) São elas [as mulheres] que veem o pó escondido atrás dos objetos e param para limpá-lo. (...) Do mesmo modo quando o olho que relê o escrito perde tempo encontrando sujeira no detalhe, trabalha como mulher. Escovar um texto, espaná-lo, são metáforas que nasceram na tarefa doméstica e a ela devem sua obsessão artesanal” (KAMENSZAIN, 2015, p.18)
} 
liberdade universal, os poemas e texto dão a ver uma costura de tempos, imagens e espaços distintos, realizada com primor e aplicação.

Teoricamente, interessa mencionar ainda a potência da leitura pela transgressão, proposta por Casanova (2002); a ideia da literatura como modo de ler e a incorporação valorativa da tradução, que, nesta abordagem, é cultural, sugerida por Damrosh (2003); ou, ainda, a exploração da cena pós-colonial de Buescu (2013), além da valorização do incomum e das relações de boa vizinhança que ela propõe.

A Literatura Mundo que pode ser lida em Cora Coralina se constrói em caminho alternativo, em voz baixa, em ritmo de viagem, observando a presença dos excêntricos e à procura de parte do que foi rasurado na memória literária entendida no plural. A expansão dos campos ajuda a evitar a miopia teórica e as armadilhas da história única e a entender o campo em expansão do nacional para o das comunidades imaginadas ou das comunidades que vêm. A suspensão do desfecho do enredo de Lui, em eterna recusa da estabilidade, talvez seja, no arcabouço poético abordado, o ponto de fuga mais significativo, a linha que se abre a todas as moscas da equivocidade, e a que, por isso mesmo, nunca deixa de dizer.

\section{REFERÊNCIAS}

ANDERSON, Benedict. Imagined Communities. Reflexions on the Origin and Spread of Nationalism. London: Verso Editions, 1983.

ANTELO, Raul. "Arquifilologias do obscuro (ou quem conta história de dia cria rabo de cotia)". Revista Letras, Curitiba, n. 94 jun./dez. p.1 a 13. 2016.

Algaravia. Discursos de Nação. Florianópolis: EdUFSC, 1998.

BENJAMIN, Walter. Magia e Técnica, Arte e Política. Trad. Sergio P. Rouanet. São Paulo: Brasiliense, 1994.

BUESCU, Helena Carvalhão. Literatura Comparada e Literatura-Mundo. A experiência do incomum e boa vizinhança. Portugal, Porto: Porto Editora, 2013.

CARVALHAL, Tania. O próprio e o alheio. São Leopoldo: Ed Unisinos, 2003.

CASANOVA. Pascale. A república Mundial das Letras. Trad. Marina Appenzeller. São Paulo: Estação Liberdade, 2002.

CORAlinA, Cora. Poemas dos Becos de Goiás e estórias mais. São Paulo: Global, 1993.

DAMROSH, David. What Is World Literature? EUA: Princeton University Press, 2003.

DELEUZE, Gilles. "O liso e o estriado". In. Mil Platôs. Capitalismo e esquizofrenia. Vol 5. Trad. Peter Pál Pelbart e Janice Caiafa. São Paulo: Ed.34, 1997.

e GUATTARI, Félix. Kafka, Por uma Literatura Menor. Trad. Cíntia Vieira da Silva. Belo Horizonte: Autêntica, 2015.

DERRIDA, Jacques. A escritura e a diferença. Trad. Maria Beatriz Marques et al. São Paulo: Perspectiva, 2009. 
La Verdad en Pintura. Trad, María Cecília González y Dardo Scavino. Buenos Aires: Paidós, 2001.

FOUCAULT, Michel. "Outros espaços". In. Outros Escritos III - Estética: Literatura e Pintura, Música e Cinema. Trad. Inês Autran D. Barbosa. Rio de Janeiro: Foense Universitária, 2001.

FREUD, Sigmund. Totem e tabu e outros trabalhos. Trad. Órizon C. Muniz. Vol.XIII. Rio de Janeiro: Imago, 1974.

FREYRE, Gilberto. Casa Grande \& Senzala. 13 ${ }^{\text {a }}$ Ed. Brasília: EdUNB, 1963.

KAMENSZAIN, Tamara. Historias de amor (y otros ensayos sobre poesía). Buenos Aires: Paidós: 2000.

"Bordado e costura do texto" e "Entrevista: A poesia trabalha contra a linguagem". In. Fala, poesia. Trad. Ariadne Costa et Al. Rio de Janeiro: Azougue; Circuito, 2015.

KIFFER, Ana e GARRAMUÑO, Florencia. Expansões Contemporâneas. Literatura e outras formas. Belo Horizonte: UFMG, 2014.

KRAUSS, Rosalind. "Sculpture in the Expanded Field”. In. October, Vol.8 (Spring, 1979), pp. 30 - 44. Disponível em:

http://www.stephengdewyer.info/PDF\%20files/Krauss,_Rosalind_Sculpture in the Expande d Field in October Vol 8 spring 1979.pdf

SANTIAGO, Silviano. "O entre-lugar do discurso latino-americano". In. Uma Literatura nos trópicos. São Paulo: Perspectiva, 1978.

O Cosmopolitismo do Pobre. Belo Horizonte: EdUFMG, 2014.

Recebido em 01/01/2020. Aceito em 01/01/2020. 